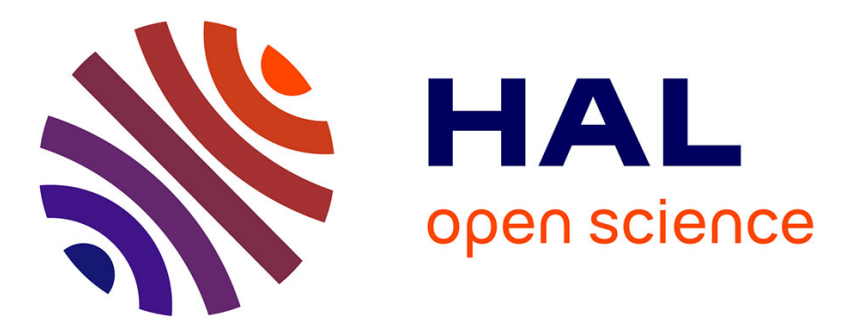

\title{
Experimental study of the miscibility of ABS/PC polymer blends and investigation of the processing effect
}

Sara Aid, A Eddhahak, Zaida Ortega, Daniel Froelich, Abbas Tcharkhtchi

\section{To cite this version:}

Sara Aid, A Eddhahak, Zaida Ortega, Daniel Froelich, Abbas Tcharkhtchi. Experimental study of the miscibility of ABS/PC polymer blends and investigation of the processing effect. Journal of Applied Polymer Science, 2017, 134 (25), pp.44975. 10.1002/app.44975 . hal-01652709

\section{HAL Id: hal-01652709 https://hal.science/hal-01652709}

Submitted on 30 Nov 2017

HAL is a multi-disciplinary open access archive for the deposit and dissemination of scientific research documents, whether they are published or not. The documents may come from teaching and research institutions in France or abroad, or from public or private research centers.
L'archive ouverte pluridisciplinaire HAL, est destinée au dépôt et à la diffusion de documents scientifiques de niveau recherche, publiés ou non, émanant des établissements d'enseignement et de recherche français ou étrangers, des laboratoires publics ou privés. 


\title{
Experimental study of the miscibility of ABS/PC polymer blends and investigation of the processing effect
}

\author{
Sara Aid, ${ }^{1}$ Anissa Eddhahak, ${ }^{1}$ Zaida Ortega, ${ }^{3}$ Daniel Froelich, ${ }^{2}$ Abbas Tcharkhtchi ${ }^{1}$ \\ ${ }^{1}$ Laboratory PIMM, CNRS UMR 8006, Arts et Métiers ParisTech, 151 bd de l'Hôpital, 75013, France \\ ${ }^{2}$ Arts et Métiers ParisTech, Savoie Technolac, rue du Lac Majeur F-73375 LE BOURGET DU LAC Cedex, Chambéry, France \\ ${ }^{3}$ Calle Juan de Quesada, 35001 Las Palmas de Gran Canaria, Las Palmas, Espagne \\ Correspondence to: A. Eddhahak (E-mail: anissa.eddhahak@ensam.eu)
}

\begin{abstract}
In the challenging prospect of developing new materials by mixing different polymers to reach a synergetic performance, the present research focuses on the study of the miscibility of two polymers: The acrylonitrile butadiene styrene (ABS) composed of a dispersed elastomeric (polybutadiene rubber) polymer embedded in a SAN thermoplastic matrix, and the polycarbonate (PC). It shall be noted that obtaining miscible polymer blends is often a difficult task because of the large size of their molecular chains and the high interfacial tension between the polymer phases. Until now, the most numerous researches developed in this field involve polymer blends obtained by compatibilization techniques in order to improve the interfacial adhesion between initial polymers. The aim of this work is to study the miscibility between ABS and PC. First, two different methods were used to mix the polymers: the twinscrew extrusion and the dissolution in a common solvent tetrahydrofuran (THF). Then, physicochemical, microscopic observation and rheological characterization were performed on samples of mixtures obtained by both extrusion processing and dissolution method. The measurement of glassy transition temperature $\left(T_{g}\right)$ by differential scanning calorimetry measurements (DSC) and dynamical mechanical thermal analysis (DMTA) have shown a partial miscibility between the two polymers
\end{abstract}

KEYWORDS: intermolecular interaction; miscibility; polymer blends; processing; rheological properties

\section{INTRODUCTION}

Many researches have been devoted to study the polymer blends in order to develop new polymer materials with technologically attractive properties. ${ }^{1,2}$ This tempting idea to mix different polymers together is particularly interesting for industrial community who are constantly looking for potential opportunities in order either to achieve a synergistic effect or to make up for some characteristics deficiencies of a specific polymer, like the case of the industry of plastics wastes recycling using blending techniques. This research work is involved in the general framework of recycling polymers derived from wastes of electrical and electronic equipment (WEEE). In this context, the blending of two thermoplastic polymers resulting from WEEE is studied: the acrylonitrile-butadiene-styrene (ABS), one of the most important rubber toughened thermoplastics with wide applications, and the polycarbonate (PC), a kind of ductile thermoplastic. $^{3}$ Prior to the processing of polymer blends, it is necessary to have preliminary idea on their potential compatibility. The latter can be defined as the appreciation of the global properties of the blend at the macroscopic scale and it is dependent on many parameters such as the system miscibility, the blend morphology, the adhesion quality between phases, their proportions and characteristics, etc. ${ }^{4}$ Thus, the final properties of the resulting blend depend on the degree of miscibility between components, composition, solvent, and morphology of the blend. ${ }^{5}$ But generally, blends of polymers present immiscibility or a partial miscibility due to the large size of the polymer chains and the high interfacial tension between the segregated phases or because of the poor adhesion between the two polymer phases. ${ }^{6}$ According to the principles of thermodynamics, when the free energy of mixing is negative, the thermodynamic miscibility and homogeneity can be reached. This condition can be fulfilled in the case when strong specific intermolecular interaction is located between the components of a blend; we can also have a case with moderate or poor interaction that induces a partial miscibility which depends on temperature and composition. One way to check the miscibility and preliminary affinity between two polymers is to study the changes in the glass transition temperature $\left(T_{g}\right)$ after blending. If the blend exhibits a single $T_{g}$, this means that the initial homopolymers are miscible 
Table I. Drying Conditions of ABS and PC Polymers

\begin{tabular}{lll}
\hline Material & $\begin{array}{l}\text { Drying } \\
\text { temperature }\left({ }^{\circ} \mathrm{C}\right)\end{array}$ & $\begin{array}{l}\text { Drying } \\
\text { time }(\mathrm{h})\end{array}$ \\
\hline $\mathrm{ABS}$ & 80 & 48 \\
$\mathrm{PC}$ & 120 & 48 \\
\hline
\end{tabular}

and when the blends exhibits more than one $T_{g}$, the system is partially miscible or immiscible. ${ }^{7}$ The methods used for $T_{g}$ Measurements are extensively described in the literature. They are either based on the measurement of heat flux over a range of temperature by differential scanning calorimeters (DSC), or on the dynamical mechanical thermal analysis (DMTA). The latter has a greater sensitivity when studying glass transition phenomena and the ability to detect all secondary motional transitions at low temperatures which influence the impact strength characteristics. ${ }^{8}$ There are also other techniques to study and examine the miscibility of the polymers blends, such as the Cole-Cole method. The Cole-Cole plot represents the variation of the loss viscosity $\left(\eta^{\prime \prime}\right)$ versus the storage viscosity $\left(\eta^{\prime}\right)$ of the blend. If it forms a semicircular relationship, then the blends are considered to be miscible. ${ }^{9-12}$ Several researches have been devoted to study immiscible blends, in particular the works of Liu et al. ${ }^{13}$ focused on the investigation of the phase inversion behavior of PA6/ABS blends. The research of Krache and Debah, ${ }^{14}$ studied different compositions of PC/ABS blends compounded by a two roller mixer, by focusing on their thermal and mechanical properties. More recently, Bärwinkel et al. ${ }^{15}$ studied the morphology formation in PC/ABS blends during their thermal processing by co-rotating twin-screw extruder and the viscosity ratio effect on this morphology. They indicated that the morphology is influenced by the processing history of the parents polymers as well as the viewing angle, relative to the melt flow direction applied during the processing.

In the present work, we proposed to study the ABS/PC blend miscibility by considering two processing techniques: the first one uses the classical twin-screw extruder, and the second one is based on an original dissolution technique of the ABS and $\mathrm{PC}$ in a common solvent tetrahydrofuran (THF). For this purpose, two methods (glass transition temperature and Cole-Cole methods) were considered for the investigation of the miscibility of the obtained blends. The aim is to study and compare the miscibility of the blends ABS/PC elaborated by two different blending techniques and using several physicochemical and rheological characterization methods.

\section{EXPERIMENTAL}

\section{Description of Materials}

The polymer materials used in this study are commercial products referenced ABS GP-22 and PC 121R supplied by Gazechim Plastics (France). Both of them are amorphous thermoplastic polymers. These polymers are commercial grades and have been chosen such as to have the same initial properties as the recycled polymers with densities equal to $1040 \mathrm{~kg} / \mathrm{m}^{3}$ and $1020 \mathrm{~kg} / \mathrm{m}^{3}$ respectively for ABS and PC grades (ISO 1183). According to the supplier, the Vicat softening temperature (VST
B) of ABS GP22 and PC $121 \mathrm{R}$ are, respectively, equal to $96^{\circ} \mathrm{C}$ and $140{ }^{\circ} \mathrm{C}$ (ISO 306) whereas the melt volume-flow rate (MVR) is equal to $19\left(\mathrm{~cm}^{3} / 10 \mathrm{~min}\right)$ and $21\left(\mathrm{~cm}^{3} / 10 \mathrm{~min}\right)$, respectively, for ABS and PC (ISO 1133).

\section{Preparation of $\mathrm{ABS} / \mathrm{PC}$ Blends}

All the materials before compounding were dried in an oven in order to remove the absorbed water. Table I summarizes the drying conditions of the materials.

The first type of blends was prepared using a classical twinscrew extruder (TSE). Two blend compositions were produced: $\mathrm{ABS} / \mathrm{PC}(30 / 70)$ and $\mathrm{ABS} / \mathrm{PC}(70 / 30)$. The processing was carried out at temperature $270^{\circ} \mathrm{C}$ and a screw speed of $300 \mathrm{rpm}$ when the PC was the principal extruder and at $215^{\circ} \mathrm{C}$ when it was the ABS. The extraduates were pelletized using a granulator then dried at $80^{\circ} \mathrm{C}$ during $12 \mathrm{~h}$. Then specimens were injection molded using a DK CODIM $175 / 410$ at $260^{\circ} \mathrm{C}$ and a mold temperature of $90^{\circ} \mathrm{C}$. The second type of blends $\mathrm{ABS} / \mathrm{PC}$ was prepared by solution technique using THF as common solvent. Solutions of ABS/PC blends were prepared by the dissolution of required amount of polymer components at a concentration of $4 \mathrm{~g} / 2 \mathrm{dL}$ in THF. For example, in the case of the blend ABS/PC $70 / 30$, the blend includes a proportion of $30 \%$ of $\mathrm{PC}$ polymer $(1.2 \mathrm{~g})$ and $70 \%(2.8 \mathrm{~g})$ of ABS polymer.

The blends solutions were agitated for $24 \mathrm{~h}$ at ambient temperature using a magnetic mixer to ensure a better mixing and homogeneity of the blend. After, the solutions were spilled into a dry and clean under ambient conditions during $24 \mathrm{~h}$.

\section{Physicochemical Characterization of ABS/PC Blends}

Dynamical Mechanical Thermal Analysis (DMTA). The dynamical mechanical thermal analysis was used in order to determine the glass transition obtained by reading the peak maximum temperature from the curve of loss modulus versus temperature. The tests were carried out using a TA instrument Q800 with a frequency equal to $1 \mathrm{~Hz}$ and a heating rate of $2{ }^{\circ} \mathrm{C} / \mathrm{min}$ from -100 to $200^{\circ} \mathrm{C}$. For the blends derived from the extrusion, the molded specimen used for DMTA test, were a tube test with a total length of $75 \mathrm{~mm}$, a width of $12.75 \mathrm{~mm}$, and a thickness of $2 \mathrm{~mm}$. For these samples, we use the bending three points test, whereas in the case of ABS/PC films (obtained by solution), we used tension test because of their extreme thinness.

Differential Scanning Calorimetry Measurements (DSC). The DSC measurements were carried out with the DSC Q10 V9.0 Build278 (TA Instruments), the scans were performed under nitrogen atmosphere from -80 to $200{ }^{\circ} \mathrm{C}$ at a heating rate of $10^{\circ} \mathrm{C} / \mathrm{min}$ with sample mass comprised between 10 and $20 \mathrm{mg}$ placed in standard capsules.

Fourier Transforms Infrared Spectrometry (FTIR). Fourier transforms infrared spectrometry was used to elucidate molecular mechanisms involved and to study the intermolecular interaction between the blends components. The FTIR measurements were carried out using PerkinElmer FTIR Spectrometry Frontier equipment. The measurement of FTIR spectra from polymeric samples is relatively fast and straightforward, providing highprecision, accurate and reproducible measurements. The test of 



Figure 1. FTIR spectra of pure ABS, pure PC, ABS/PC blends (70/30) made by extrusion (EXT) and ABS/PC blends (70/30) made by solution (SOL) from (a) 600 to $1300 \mathrm{~cm}^{-1}$; (b) 1300 to $1600 \mathrm{~cm}^{-1}$; (c) 1600 to $2000 \mathrm{~cm}^{-1}$; (d) 2000 to $3200 \mathrm{~cm}^{-1}$. [Color figure can be viewed at wileyonlinelibrary. com]

FTIR-MIR was carried out using transmission mode, 16 scans for each sample with a resolution of $4 \mathrm{~cm}^{-1}$. Note that in order to improve the sensitivity of this method and follow accurately the dynamics of orientation, FTIR spectroscopy has been coupled to a polarization modulation technique. For the ABS/PC blends obtained by the extrusion process, thin films were prepared from the extraduates grains by compression molding into plates of $2 \mathrm{~mm}$ of thickness at $250^{\circ} \mathrm{C}$ and 200 bars during $90 \mathrm{~s}$.

Rheological Tests. The rheological measurements were carried out with a rheometer model Anton Paar MCR 502, at different temperatures, in mode plate and plate geometry in order to evaluate the viscosity of polymers (individual and blends) at different shear rates, on the one hand and the miscibility of the ABS/PC blends using the Cole-Cole method, on the other one. Two types of measurements were carried out at the temperature of $220^{\circ} \mathrm{C}$. For the viscosity measurements, a frequency of $1 \mathrm{~Hz}$ is considered whereas a frequency range from $0.1 \mathrm{~Hz}$ to $100 \mathrm{~Hz}$ with an imposed strain of $0.1 \%$ is considered for the Cole-Cole method by evaluating the viscous and elastic responses.
Morphology. Two types of samples were used for morphological observations: the first ones are molded specimens used for impact testing which were previously fractured at room temperature by the classical tensile test, and the second ones are films of blends (derived from solution process). Furthermore, we carried out a chemical attack with acetone on the different blends (extruded ones and those obtained by dissolution), in order to dissolve the ABS phase only. Then the samples were dried and coated with thin layer of gold, about $50 \AA$ of thick before to be observed using a scanning electron microscopy (SEM) model MEB HITACHI 4800.

\section{RESULTS AND DISCUSSION}

\section{Molecular Interaction}

Most polymer blends are immiscible due to the high degree of polymerization, which predicts the small combinatorial entropy, based directly on Flory-Huggins equations. ${ }^{16}$ In order to obtain a one-phase system in polymer blends, it is essential to ensure that favorable specific intermolecular physical or chemical interactions exist, such as hydrogen bonding, for instance. 

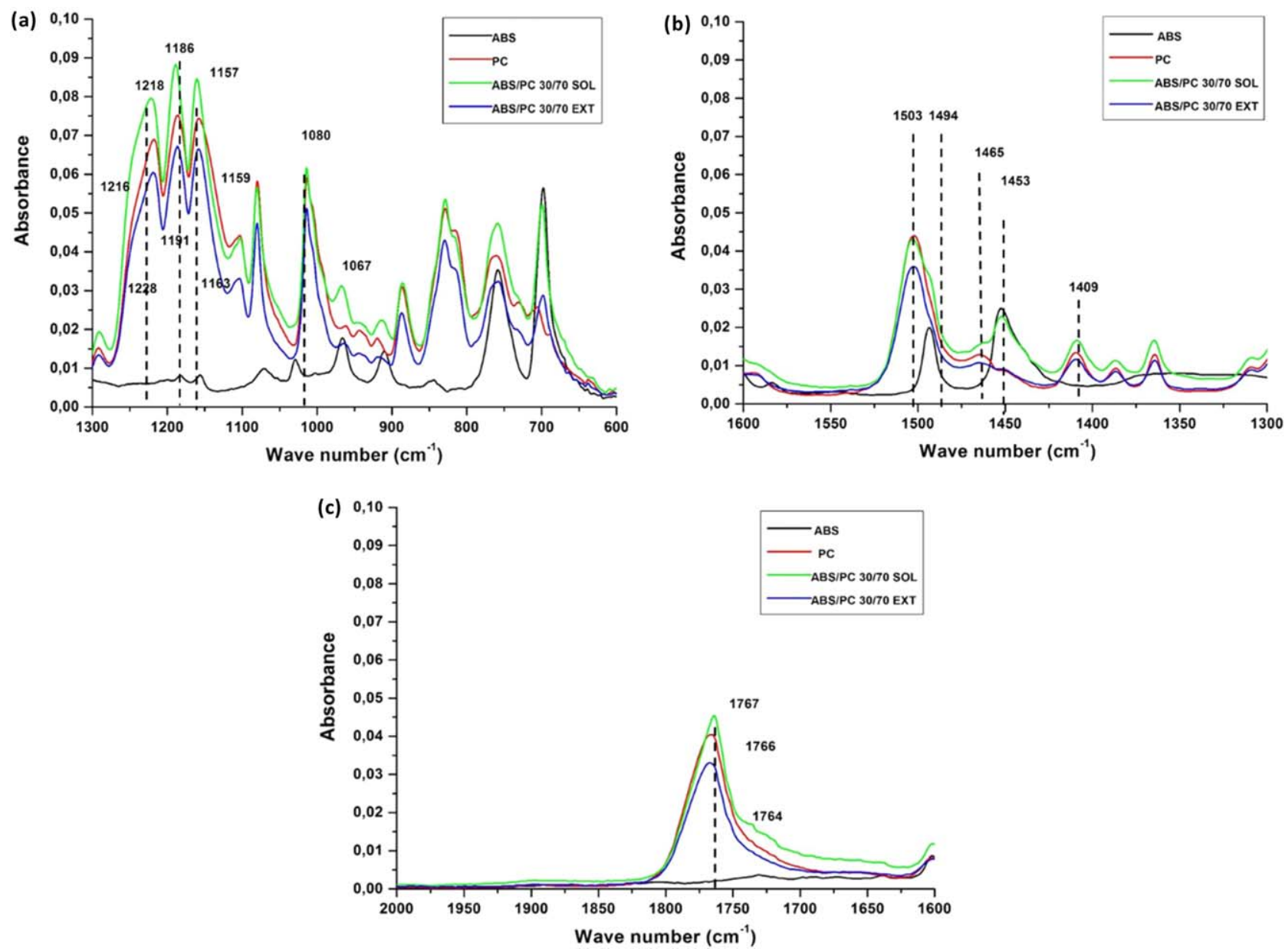

Figure 2. FTIR spectra of pure ABS, pure PC, ABS/PC (30/70) made by extrusion (EXT), and ABS/PC (30/70) made by solution (SOL) from (a) $600 \mathrm{~cm}^{-1}$ to $1300 \mathrm{~cm}^{-1}$; (b) $1300 \mathrm{~cm}^{-1}$ to $1600 \mathrm{~cm}^{-1}$; (c) $1600 \mathrm{~cm}^{-1}$ to $2000 \mathrm{~cm}^{-1}$. [Color figure can be viewed at wileyonlinelibrary.com]

In homogeneous blends, the final properties are often obtained by an arithmetic average of the properties of the single components (classical mixture law). Homogeneous miscibility in polymer blends requires a negative free energy of mixing $(\Delta G<0)$, but also a mixing enthalpy near zero or negative $(\Delta H \leq 0)$. The formation of hydrogen bonds usually induces miscibility of the blends; the latter are therefore founded to be partially or fully miscible due to the presence of these interassociated hydrogen bonds.

Figure $1(\mathrm{a}-\mathrm{d})$ presents the spectra of ABS/PC 70/30 obtained by both extrusion and dissolution methods (note that the same spectra are presented at different wave number ranges in order to better see the peaks). Observation of FTIR spectra shows characteristic peaks of ABS and PC polymers. Moreover, one can notice some interactions between $\mathrm{PC}$ and $\mathrm{ABS}$ components mainly in the case of ABS/PC blend prepared under THF.

Besides, it is important to highlight that solvent does not impact the spectra of individual polymers in the blend. This is confirmed by comparing the spectra of PC and ABS raw pellets, on the one hand and films of pure ABS and pure PC, obtained by dissolution on the other one. As no peaks or shifts in reference peaks are observed, it can be concluded that solvent was completely evaporated from the films and is not therefore affecting spectra.

Once the solvent effect was checked, composition and spectra are superposed and analyzed, so that the influence of both composition and blending method can be studied. The extruded material showed spectra more similar to those of the predominant component polymer in the blend. Indeed, extruded blends with $70 \%$ of ABS show a similar spectrum to ABS, whereas extruded blends with $70 \%$ of PC shows a spectrum similar to that of PC (Figure 2).

A general view of spectra for all prepared blends show peaks shifting and bands widening; the former is clearly observed in the characteristic peaks for each component (summarized in Table II), while the second one can be easily observed in the region of 1100 to $1300 \mathrm{~cm}^{-1}$ (at $1218 \mathrm{~cm}^{-1}$ ), 1700 to 1800 (at $1767 \mathrm{~cm}^{-1}$ ), and 1450 to $1550 \mathrm{~cm}^{-1}$.

Underlined in green the most significant peaks for PC and in blue for ABS (Table II) (reference peaks taken from Ref. 17).

As it can be shown in Figure $2(\mathrm{a}-\mathrm{c})$, in the case of blends with PC as major component, similar behavior is observed. In fact, extruded blend spectrum is more similar to the $\mathrm{PC}$ one, while 
Table II. Characteristic Peaks of ABS/PC Blends (FTIR Spectra Analysis)

\begin{tabular}{|c|c|c|c|c|c|c|}
\hline & PC & ABS & $\begin{array}{l}\text { ABS/PC } \\
30 / 70 \text { EXT }\end{array}$ & $\begin{array}{l}\text { ABS/PC } \\
30 / 70 \mathrm{SOL}\end{array}$ & $\begin{array}{l}\text { ABS/PC } \\
70 / 30 \text { EXT }\end{array}$ & $\begin{array}{l}\text { ABS/PC } \\
70 / 30 \text { SOL }\end{array}$ \\
\hline $\mathrm{C}-\mathrm{H}$ & 829 & 843 & 829 & 828 & 831 & 827 \\
\hline $\begin{array}{c}\text { Trans-2-butene- } \\
\text { 1,4-diyl (PB) }\end{array}$ & - & 966 & - & 966 & 966 & 966 \\
\hline $\mathrm{O}-\mathrm{C}-\mathrm{O}$ & 1013 & - & 1014 & 1015 & 1014 & 1014 \\
\hline $\mathrm{C}-\mathrm{C}-\mathrm{C}$ & 1080 & - & 1080 & 1081 & 1081 & 1081 \\
\hline CHin butadiene & - & 1455 & - & 1453 & 1454 & 1453 \\
\hline Aromatic C & 1504 & 1494 & 1500 & 1494,1503 & 1496,1506 & 1493,1506 \\
\hline $\mathrm{C}=\mathrm{O}$ & 1767 & - & 1767 & 1764 & 1770 & 1764 \\
\hline $\mathrm{C}=\mathrm{N}$ & - & 2239 & - & 2243 & 2239 & 2239 \\
\hline $\mathrm{C}-\mathrm{CH}_{3}$ & 2969 & - & 2971 & - & 2969 & 2969 \\
\hline $\mathrm{C}-\mathrm{H}, \mathrm{CH}_{2}$ & - & 2855, 2922 & 2855,2933 & 2852, 2919 & 2855,2926 & 2852,2920 \\
\hline
\end{tabular}
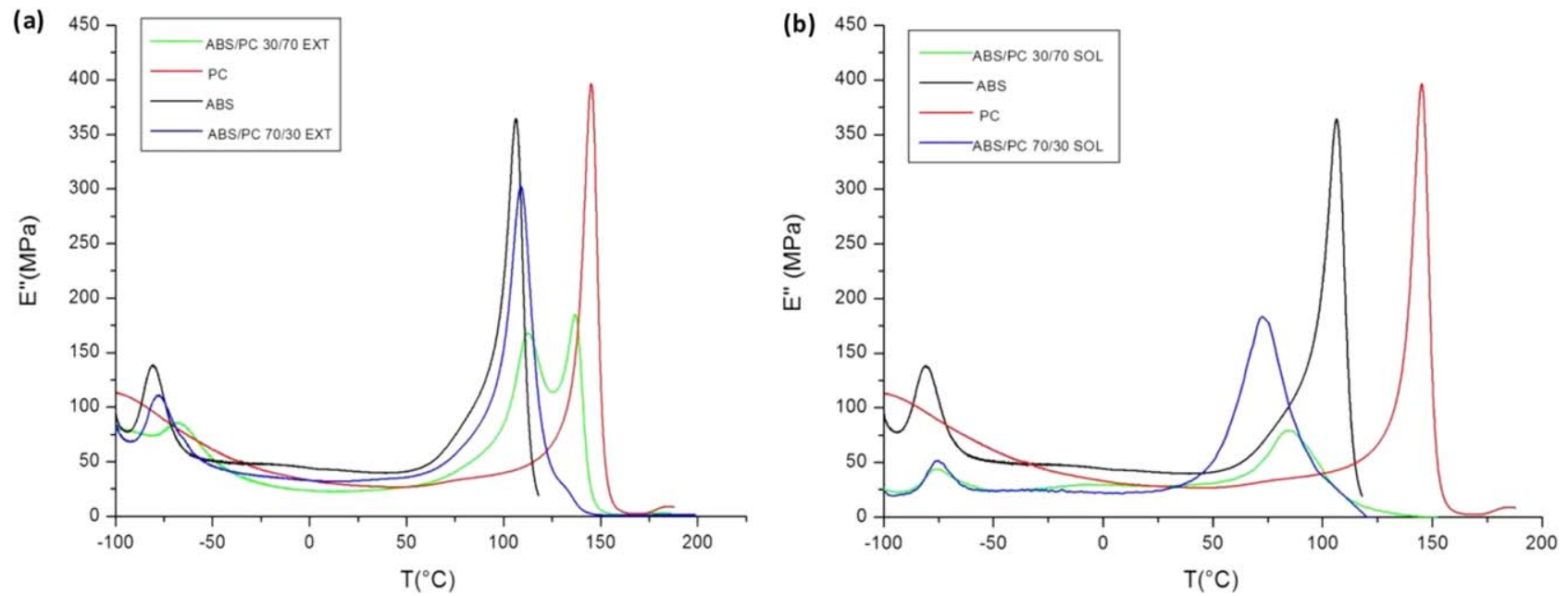

Figure 3. Rheological results of loss modulus as function of temperature for ABS/PC blends made by (a) extrusion and (b) dissolution. [Color figure can be viewed at wileyonlinelibrary.com]
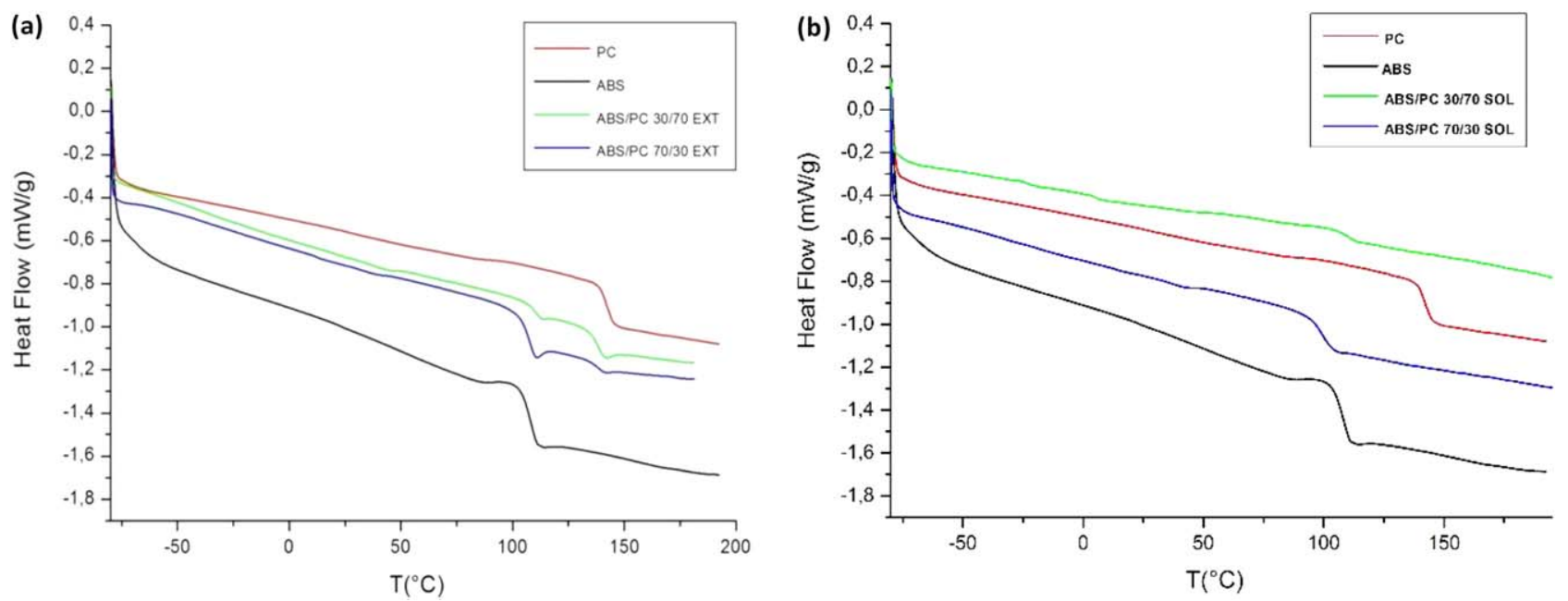

Figure 4. DSC results of heat flow for ABS/PC blends made by (a) extrusion and (b) dissolution. [Color figure can be viewed at wileyonlinelibrary.com] 


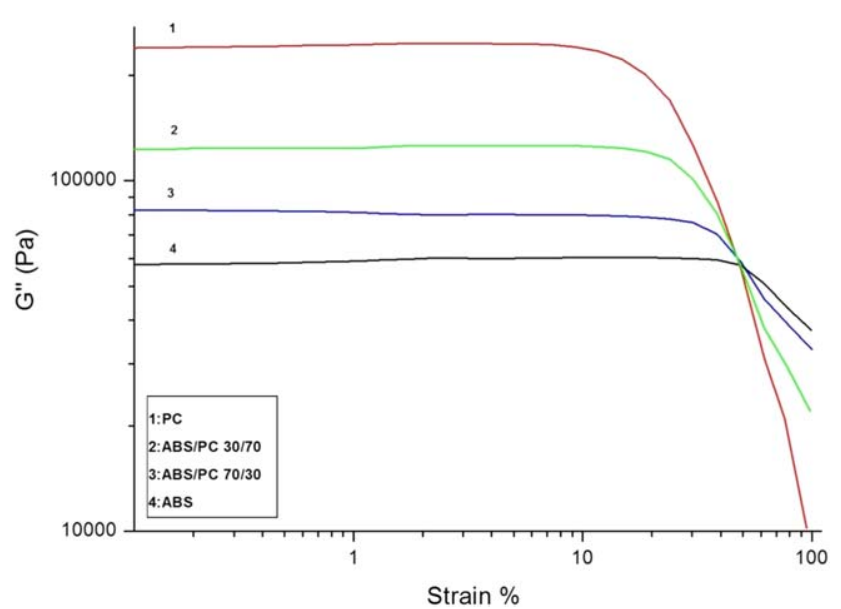

Figure 5. Determination of the dynamic linear region of ABS/PC extruded blends, $\left(f=100 \mathrm{~Hz}, T=220^{\circ} \mathrm{C}\right)$. [Color figure can be viewed at wileyonlinelibrary.com]

the blend made by solution in THF shows intermediate behavior, although with some peaks more resembling to ABS.

As explained above, shifts in wave number or bands widening are usually taken as evidences of chemical interactions between the components of a blend and indicate some miscibility degree. ${ }^{18}$ So, even if no new peaks appear in the spectra, these changes, observed mainly for the solvent casted blends show some degree of interaction between the polymer components in the blend.

\section{Study of the Blend Miscibility}

Glass Transition Temperature. The most known ways often used to check the miscibility of a polymeric system are the different thermal analysis techniques. If the system is immiscible, $T_{g}$ values of the individual polymers would not change after mixing them. On the contrary, if the system is miscible, a single common $T_{g}$ is obtained for the polymer blend. In Figure 3(a) (case of the extruded blend), the variation of the loss modulus versus temperature reveals that the $\mathrm{PC}$ transition is around $145^{\circ} \mathrm{C}$, the ABS has two transitions, $-82^{\circ} \mathrm{C}$ and $106^{\circ} \mathrm{C}$ matching to the transitions of butadiene and SAN phases, respectively. The analysis of the DMTA blends curve reveals that the peaks at high temperature region in the blends were shifted comparing to those of the parent polymers. In fact, the blends ABS/PC show a transitional attitude, since the two blends present initially three transitions. The first blend with $70 \%$ of PC Figure $3(\mathrm{a})$ has transitions at $-71{ }^{\circ} \mathrm{C}, 113^{\circ} \mathrm{C}$, and $136^{\circ} \mathrm{C}$, the second one with $30 \%$ of PC shows transitions at $-78^{\circ} \mathrm{C}, 109^{\circ} \mathrm{C}$, and $132^{\circ} \mathrm{C}$. The shifts observed at high temperature are as important as those observed in lower temperature. This phenomenon, where each phase interacts with the other one, and transitions shifts are detected, is synonym of some degree of miscibility. According to the work of Chun et al., ${ }^{19}$ the new transitions observed at $109,113,132$, and $136^{\circ} \mathrm{C}$ correspond to the miscibility of the PC phase with the SAN phase. However, one can also observe in lower temperature regions, transitions at -72 and $-78^{\circ} \mathrm{C}$. These shifts are due to a slight interaction between the butadiene and the polycarbonate phases. We notice, besides, a decrease in the intensity of the loss modulus peak which is due to energy absorption, thereby confirming the creation of new links and interactions.

In the case of mixtures obtained by solution [Figure 3(b)], the DMTA results obtained for the ABS/PC 30/70 blend exhibits two transitions peaks: one at low temperature at $-76^{\circ} \mathrm{C}$ and the other at $84^{\circ} \mathrm{C}$. The blend $\mathrm{ABS} / \mathrm{PC} 70 / 30$ exhibits the same behavior, a first transition at $-76^{\circ} \mathrm{C}$ and a second one at $74{ }^{\circ} \mathrm{C}$. According to the theory of transitions mixtures, a single $T_{g}$ peak at high temperature for the mixture obtained by dissolution, traduces an improvement of the miscibility in comparison with the previous type of processing blending (TSE). Besides, having a significant decrease of $T_{g}$ can also be explained by the solvent which could have played the role of plasticizer, thereby lowering the $T_{g}$ of the mixture. ${ }^{20,21}$

On the other hand, in order to confirm the DMTA results, we tested the miscibility of the different ABS/PC blends using
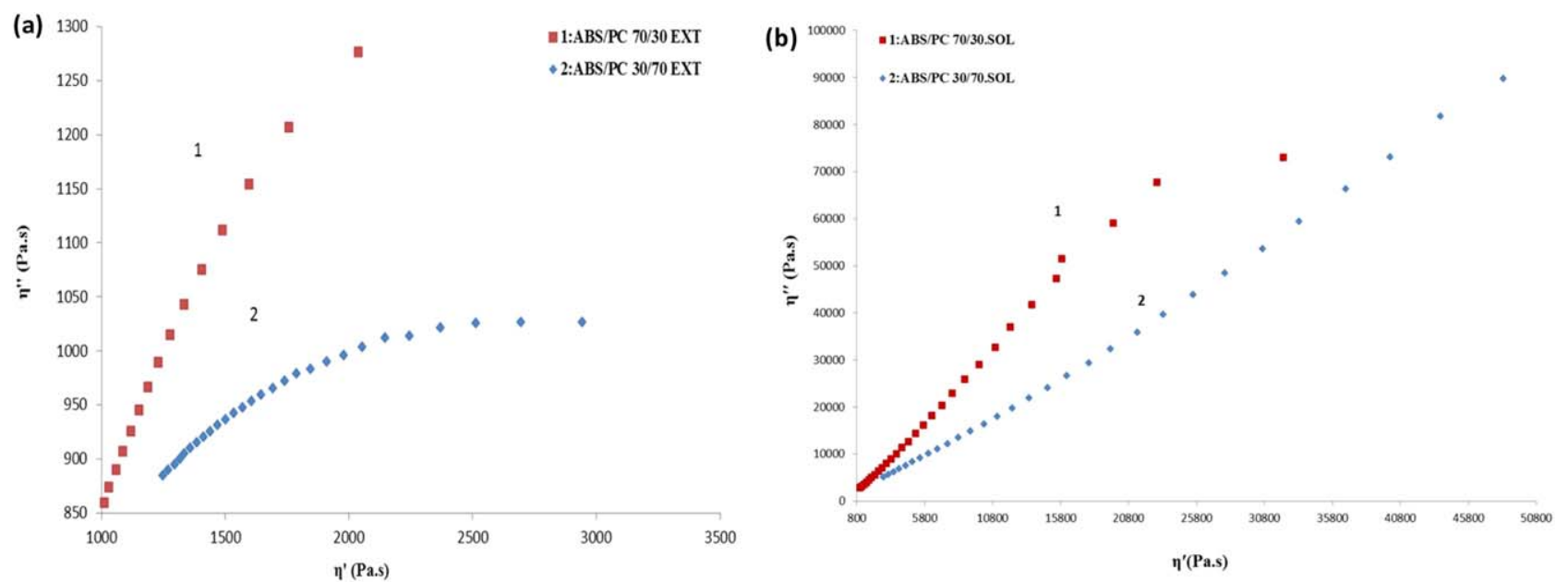

Figure 6. Rheological results of complex viscosity measurement for ABS/PC made by (a) extrusion and (b) dissolution at $220^{\circ} \mathrm{C}$. [Color figure can be viewed at wileyonlinelibrary.com] 
differential calorimetry analysis technique (DSC). The DSC results confirmed those obtained by DMTA. In fact, with the extrusion mode, the blends exhibit at high temperature two transition temperatures [Figure 4(a)], whereas with the dissolution mode [Figure 4(b)], a single $T_{g}$ is observed at high temperature for both $\mathrm{ABS} / \mathrm{PC}$ blends, 30/70 and 70/30. Note that
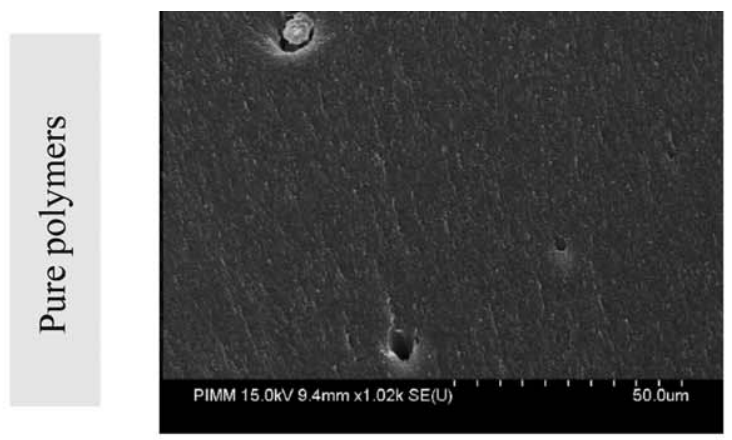

(a)

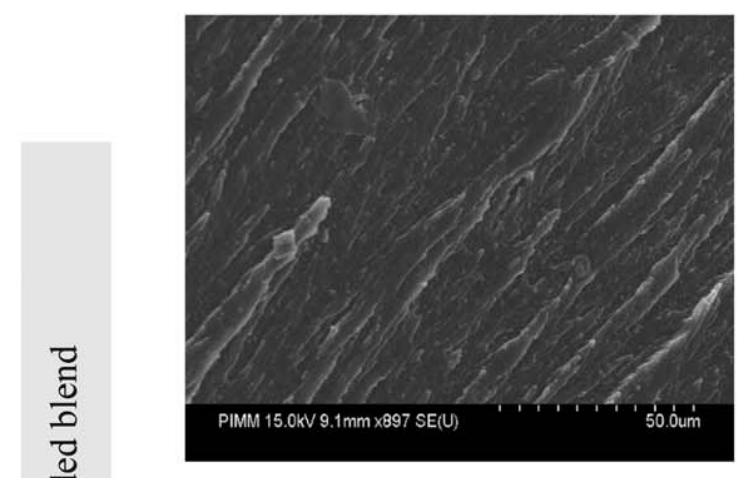

(c)

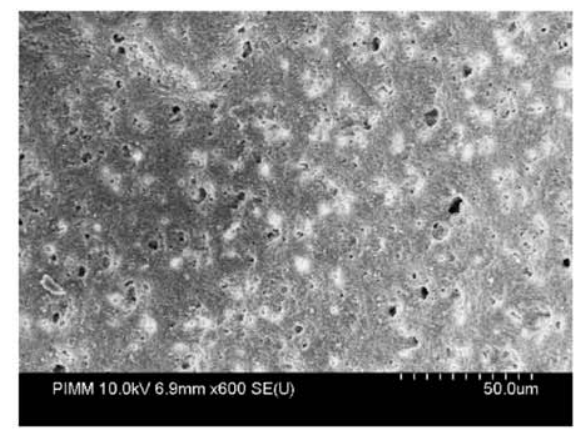

(e)

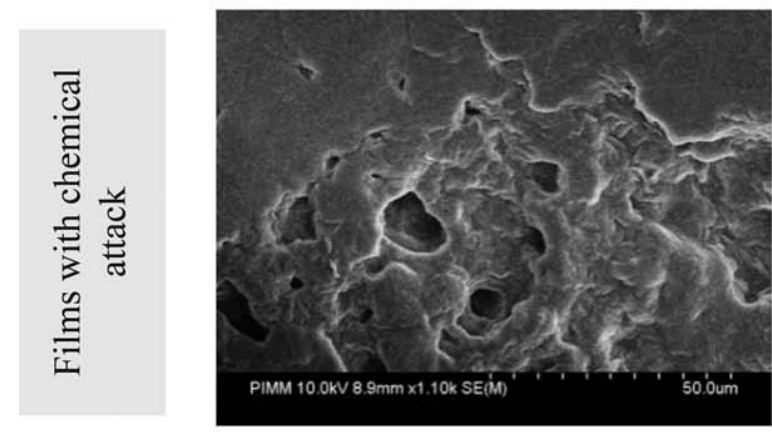

(g)

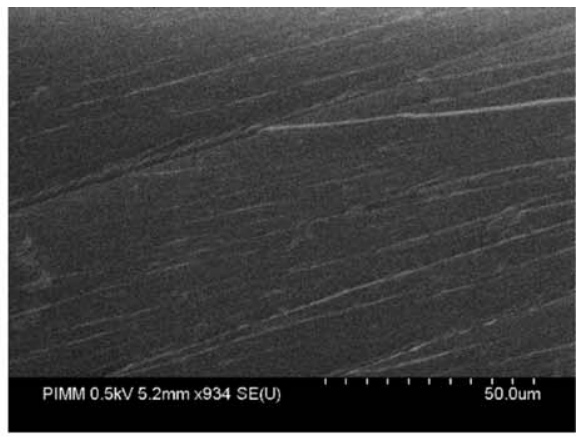

(b)

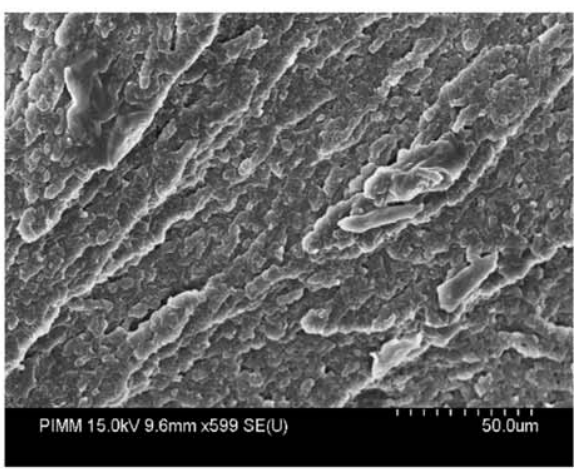

(d)

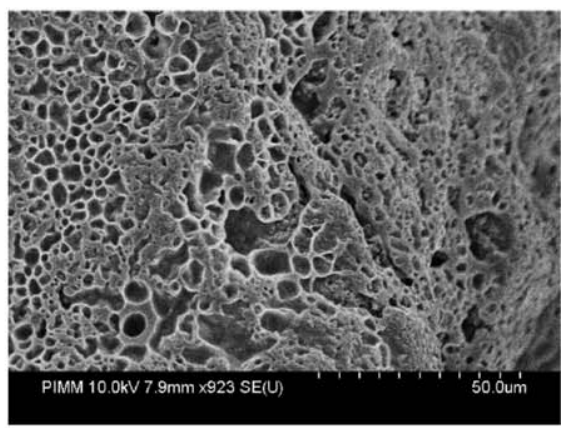

(f)

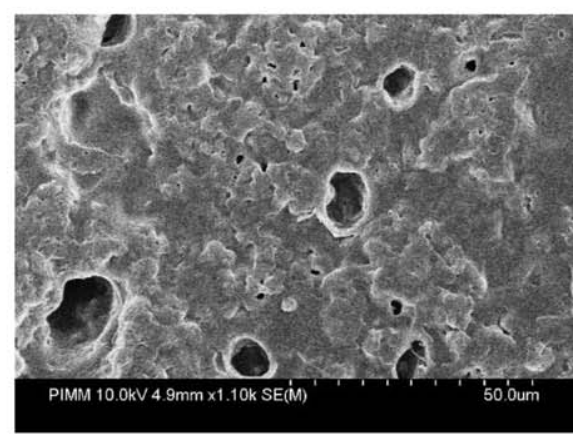

(h)

Figure 7. SEM micrographs of fractured specimen: (a) ABS, (b) PC, (c) ABS/PC (30/70), (d) ABS/PC (70/30), fractured specimen with chemical attack, (e) $\mathrm{ABS} / \mathrm{PC}$ (30/70), (f) ABS/PC (70/30) and films obtained by dissolution (g) ABS/PC (30/70), (h) ABS/PC (70/30), respectively. 
transitions at lower temperature for $\mathrm{ABS} / \mathrm{PC}$ blends was not observed since the DSC equipment is limited in terms of test in lower temperature $\left(T_{\lim }=-80^{\circ} \mathrm{C}\right)$.

The present results demonstrate that the ABS/PC is characterized by a partial miscibility. The degree of miscibility is better in the case of blends made by solution than those obtained by the extrusion process.

Cole-Cole Method. In general, pure polymers exhibit a linear viscoelastic (LVE) behavior in the low strain region, i.e., the elastic modulus $\left(G^{\prime}\right)$ and loss modulus $\left(G^{\prime \prime}\right)$ are independent of the applied strain. ${ }^{22}$ Figure 5 shows the evolution of the loss modulus $\left(G^{\prime \prime}\right)$ versus the applied strain (from 0.1 to $100 \%$ ) at $220^{\circ} \mathrm{C}$ for a frequency $f=100 \mathrm{~Hz}$ for the $\mathrm{ABS} / \mathrm{PC}$ extruded blends. One can observe a "plateau" corresponding to the linear viscoelastic behavior of the materials. When the applied strain exceeds the critical value, the elastic modulus decreases with increasing deformation. Note that the same tendency was noted for the blends prepared under THF solution. To be sure that all tests will be performed in the linear region, all measurements were performed in a frequency sweep mode using a given small deformation of $0.1 \%$.

The method developed by Cole-Cole representing the relationship between the real and the imaginary parts of the complex viscosity, respectively $\left(\eta^{\prime}, \eta^{\prime \prime}\right)$ allows the validation of the polymer blends compatibility. Indeed, by plotting $\eta^{\prime \prime}$ values in function of $\eta^{\prime}$ ones, one can evaluate the compatibility of the blends by observing the shape of the obtained curves. If the blend is readily miscible and homogeneous, the curves $\eta^{\prime \prime}=f\left(\eta^{\prime}\right)$ are quite smooth and have the shape of a semicircle. However, the occurrence of deviations or disordered points on the curve can reflect a poor homogeneity of the blends components. ${ }^{6}$ Figure 6(a) presents plots of $\eta^{\prime \prime}$ versus $\eta^{\prime}$ for the ABS/PC blends obtained by extrusion processing. As seen in this figure, the curve of the blend ABS/PC (30/70 presents a shape of a semicircle). This is not the case for the second blend with $30 \% \mathrm{PC}$ and $70 \%$ ABS which exhibit a different behavior (deviation of the Cole-Cole plots). This finding supports the aforementioned $T_{g}$ results, on the one hand, and the literature results about the partial miscibility of the ABS/PC blends, on the other one. In fact, previous researches highlighted a good miscibility of the PC with the SAN phase of ABS and a low miscibility between the PC and Butadiene phases. ${ }^{2,19}$ By analogy, using the ColeCole method in the case of blends obtained by THF dissolution [Figure 6(b)], the curves show some deviations, but one can see a slight curvature in the case of the blend with $30 \%$ of PC more pronounced than the one noticed with extruded blends ABS/PC 70/30. This last finding let deduce that the method of the dissolution has enhanced the miscibility of the ABS/PC 70/30.

\section{SEM Observations}

The study of the morphology of fractured by mechanical tensile test surface using SEM technique has identified the different phases in the partially miscible ABS/PC blends. Figure 7 (a) shows the ABS microstructure which reveals the presence of two phases: the SAN continuous matrix and some inclusions corresponding to the particle of polybutadiene. Whereas Figure 7(b) shows one homogenous phase corresponding to the PC one.
Figure $7(\mathrm{c}, \mathrm{d})$ show the microstructure of fracture surfaces of samples ABS/PC (30/70) and (70/30), respectively. The microstructure morphology exhibits a fibrillar tendency oriented along the direction of propagation of the crack. We notice that it is almost impossible to distinguish between matrix and the dispersed phase, which tends to illustrate the good adhesion between the two phases in these mixtures. Then we carried out the chemical attack with acetone on these samples and the micrographs are presented in the Figure 6(e,f).

As expected, the micrographs exhibit heterogeneous structure in each blend, characterized by a dispersed nodular particle/matrix morphology. The ABS phase appears as holes or "porosity" (dark phase) in the blends which are induced by the dissolution of the ABS in the acetone. They form a dispersed phase whose size depends on the composition. Furthermore, we used the processing software Image $J$ to calculate the size, the area occupied by the holes, and the percentage of these holes relative to the overall surface. For the blend containing 30\% of ABS, the size of holes ranges between 3 and $18 \mu \mathrm{m}$, whereas in the case of blend with $70 \% \mathrm{ABS}$, the holes are bigger and range between 2 and $44 \mu \mathrm{m}$. However, the blend ABS/PC (70/30) exhibits more holes than the other one since the ABS is the predominant phase. In the case of the films of ABS/PC blends obtained by THF dissolution, the micrographs [Figure $7(\mathrm{~g}, \mathrm{~h})$ ] show a similar behavior with a dispersed morphology characterized by a number of holes more important for ABS/PC (70/30) blend comparing to $\mathrm{ABS} / \mathrm{PC}$ (30/70). Furthermore, it was founded that in the case of blends ABS/PC 70/30 made by extrusion, the holes represented $44 \%$ of the overall surface, whereas in the case of blend obtained by THF dissolution, the surface of the holes represents only $5 \%$. This finding illustrates the best dissolution of the ABS in the PC phase in the case of mixtures obtained by dissolution method.

\section{CONCLUSIONS}

In this work, an experimental study was carried out in order to study the miscibility of the ABS/PC blend. Two types of processing were considered to elaborate the blends: the first one was the twin-extrusion process and the second one was the dissolution under THF. In the case of extruded blend, the experimental results have shown a partial miscibility. In order to improve the blends miscibility, we proceeded to formulate mixtures in solution using a common solvent (THF) and the results obtained for the blends made by solution showed a better miscibility than in the extruded case. Furthermore, the analysis of FTIR spectra and the morphological observations highlighted a better interaction between ABS and PC parent polymers in comparison with the extruded blends. Despite the improvement of the miscibility of these mixtures using the dissolution technique, it shall be noted that the THF solvent can be used only at a laboratory scale because of health security precautions. Although the perfect miscibility of extruded blends was not reached, it is important to highlight that further investigations are needed to evaluate the macroscopic properties of this blend such as the mechanical behavior. Work is now in progress to study the mechanical properties of ABS/PC blends with different compositions of parent polymers. 


\section{ACKNOWLEDGMENTS}

The authors gratefully acknowledge the financial support of the Chaire Mines Urbaines, Eco-Systemes and ParisTech Fondation.

\section{REFERENCES}

1. Seong, D.-W.; Yeo, J.-S.; Hwang, S.-H. J. Ind. Eng. Chem. 2016, 36, 251.

2. Balart, R.; López, J.; García, D.; Dolores Salvador, M. Eur. Polym. J. 2005, 41, 2150.

3. Yin, Z. N.; Fan, L. F.; Wang, T. J. Mater. Lett. 2008, 62, 2750.

4. Vasile, C.; Schneider, I. A. Eur. Polym. J. 1971, 7, 1205.

5. Marwat, Z. K.; Baloch, M. K. Eur. Polym. J. 2015, 66, 520.

6. Chevallier, C.; Becquart, F.; Taha, M. Mater. Chem. Phys. 2013, 139, 616.

7. Fekete, E.; Földes, E.; Pukánszky, B. Eur. Polym. J. 2005, 41, 727.

8. Wetton, R. E.; Corish, P. J. Polym. Test. 1988, 8, 303.

9. Kim, H. L.; Rana, D.; Kwag, H.; Choe, S. Korea Polym. J. 2000, 8, 34 .

10. Cho, K.; Lee, B. H.; Hwang, K.-M.; Lee, H.; Choe, S. Polym. Eng. Sci. 1998, 38, 1969.

11. Joshi, M.; Butola, B. S.; Simon, G.; Kukaleva, N. Macromolecules 2006, 39, 1839.
12. Barczewski, M.; Matykiewicz, D.; Andrzejewski, J. Macromol. Res. 2015, 23, 850.

13. Liu, X.-Q.; Bao, R.-Y.; Liu, Z.-Y.; Yang, W.; Xie, B.-H.; Yang, M.-B. Polym. Test. 2013, 32, 141.

14. Krache, R.; Debah, I. Mater. Sci. Appl. 2011, 2, 404.

15. Bärwinkel, S.; Seidel, A.; Hobeika, S.; Hufen, R.; Mörl, M.; Altstädt, V. Materials 2016, 9, 659.

16. Flory, P. J. Principles of Polymer Chemistry; Cornell University Press: Ithaca, United States, 1953

17. Stuart, B. H. Infrared Spectroscopy Fundamentals Applications; John Wiley \& Sons, Ltd.: Dartford, Kent, UK, 2004; p 71.

18. Arnold, J. C.; Watson, T.; Alston, S.; Carnie, M.; Glover, C. Polym. Test. 2010, 29, 459.

19. Chun, J.-H.; Maeng, K.-S.; Suh, K.-S. J. Mater. Sci. 1991, 26, 5347.

20. Hadjichristidis, N.; Hirao, A.; Tezuka, Y.; Prez, F. D. Complex Macromolecular Architectures: Synthesis, Characterization, and Self-Assembly; John Wiley \& Sons: (Asia) Pte Ltd.: Singapore, 2011.

21. Ueberreiter, K. Plasticizing and Plastics Process; American Chemical Society: Washington, DC, 1965; p 35.

22. Ferry, JD. Viscoelastic Properties of Polymers; Wiley: New York, 1980 